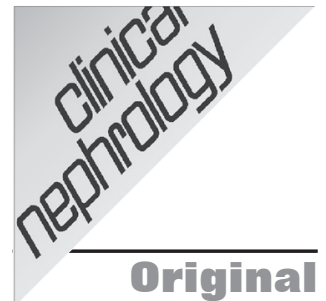

๑2016 Dustri-Verlag Dr. K. Feistle ISSN 0301-0430

DOI $10.5414 / C N 108580$

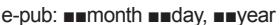

Key words

systemic sclerosis MDRD - CKD-EPI chronic kidney disease

\section{Received}

February 4, 2015; accepted in revised form February 10, 2016

Correspondence to Antonietta Gigante, mun $\mathrm{MD}, \ldots$ ?

Sapienza, University of Rome, Department of Clinical Medicine-Clinical Immunology Unit, Viale dell'Università 37, 00185 Rome, Italy antonietta_gigante@ yahoo.it

\title{
Evaluation of estimated glomerular filtration rate and clinical variables in systemic sclerosis patients
}

\author{
Antonietta Gigante, Bmm. Barbano, Gmm. Granata, Smm. Quarta, Amm. \\ Amoroso, Fmm. Salsano, Rmm. Cianci, and Emm. Rosato mur Please complete \\ authors firstnames for PubMed citation \\ Department of Clinical Medicine, Clinical Immunology Unit-Scleroderma Center, \\ Sapienza, University of Rome, Rome, Italy
}

Abstract. Objectives: The most important renal complication of systemic sclerosis $(\mathrm{SSc})$ is scleroderma renal crisis (SRC). Many patients demonstrate less severe renal complications, most likely associated with reduced renal blood flow and a consequent reduction in glomerular filtration rate (GFR). The mechanism of this slowly progressive form of chronic renal disease is unclear. The aim of this study was to evaluate GFR by the Chronic Kidney Disease Epidemiology Collaboration (CKD-EPI) and the 7-variable Modification of Diet and Renal Disease (MDRD) equations in SSc patients and to correlate estimated GFR (eGFR) with clinical variables of the disease. Methods: 105 unselected and consecutive patients with SSc were enrolled. Serum creatinine was measured in all patients and GFR was estimated by 7-variable MDRD and CKD-EPI equations. Nailfold videocapillaroscopy was performed in all patients. Results: The mean value of eGFR evaluated by both 7-variable MDRD and CKD-EPI was significantly different $(p<0.0001)$ in the three capillaroscopic groups and correlated negatively with the severity of capillaroscopic damage (early: $95 \pm 16 \mathrm{~mL} / \mathrm{min}$ and $101 \pm 12$ $\mathrm{mL} / \mathrm{min}$, active: $86 \pm 25 \mathrm{~mL} / \mathrm{min}$ and $95 \pm 17$ $\mathrm{mL} / \mathrm{min}$, late: $76 \pm 21 \mathrm{~mL} / \mathrm{min}$ and $82 \pm 21$ $\mathrm{mL} / \mathrm{min})$. The mean value of eGFR evaluated by 7 -variable MDRD $(97 \pm 23 \mathrm{~mL} / \mathrm{min}$ vs. $74 \pm 15 \mathrm{~mL} / \mathrm{min}, \mathrm{p}<0.0001)$ and CKD-EPI $(0.83 \pm 0.20 \mathrm{~mL} / \mathrm{min}$ vs. $0.68 \pm 0.10 \mathrm{~mL} / \mathrm{min}$, $\mathrm{p}<0.0001)$ was significantly higher in SSc patients without history of digital ulcers than in those with. Conclusion: We can conclude that in SSc patients without renal involvement, eGFR decreases with the progression of digital vascular damage.

\section{Introduction}

Several patterns of renal pathology are recognized in patients with systemic sclero- sis (SSc); almost all involve vascular abnormalities. The most important renal complication of SSc is scleroderma renal crisis (SRC). Many patients demonstrate less severe renal complications (e.g., abnormal renal vascular resistance indices), most likely associated with reduced renal blood flow and a consequent reduction in glomerular filtration rate (GFR). The mechanism of this slowly progressive form of chronic renal disease is unclear [1]. Therefore, chronic kidney disease (CKD) could be evaluated by estimated GFR (eGFR).

In patients with SSc, Kingdon et al. [2] showed that eGFR calculated using the 7-variable Modification of Diet in Renal Disease (MDRD) equation and Cockcroft-Gault formula correlated with GFR measured using a radioisotope clearance method. In SSc patients with normal serum creatinine $(\mathrm{sCr})$, the Chronic Kidney Disease Epidemiology Collaboration (CKD-EPI) is a useful formula to assess GFR [3].

The aim of this study was to evaluate the presence of renal involvement in SSc patients by GFR estimated by 7-variable MDRD and CKD-EPI equations and to correlate eGFR with clinical variables of the disease.

\section{Materials and methods}

150 consecutive patients who met the American College of Rheumatology/European League Against Rheumatism Collaborative Initiative criteria for $\mathrm{SSc}$ were enrolled in this study [4]. Of these, 105 patients were eligible (92 female and 13 male; mean age $54.9 \pm 14.4$ years). Patients with 
elevated $\mathrm{sCr}$, elevated blood urea, urinary tract infection, abnormal urinary sediment, glomerulonephritis, kidney stones, antiphospholipid-associated nephropathy, diabetes, cardiovascular disease (hypertension, myocardial infarction, arrhythmias, heart failure), hyperlipidemia, coagulopathy, SRC, or smokers were excluded.

Mean duration of Raynaud's phenomenon and disease were $10.4 \pm 5.8$ years and $9.1 \pm 5.1$ years, respectively. 60 patients had limited cutaneous SSc and 45 had diffuse cutaneous SSc as defined by Le Roy et al. [5].

All SSc patients underwent treatment with calcium channel blockers (nifedipine $30 \mathrm{mg}$ /day). No patients were treated with immunosuppressive agents (e.g., cyclophosphamide or mycophenolate mofetil).

No patients were undergoing treatment with angiotensin-converting enzyme inhibitors and/or angiotensin II receptor blockers. Three patients had elevated $\mathrm{sCr}$ values.

Written consent was obtained according to the Declaration of Helsinki and the study was approved by the Ethics Committee of Sapienza University.

\section{Laboratory parameters}

Laboratory investigations included $\mathrm{sCr}$, blood urea nitrogen, sodium, potassium, uric acid, and albumin. SCr was measured using a Jaffe alkaline picrate assay (Abbott Aeroset analyzer) [6].

\section{Calculation of GFR}

GFR was calculated using the 7 variables developed in the MDRD study. This formula uses demographic and serum variables but does not require urine collection: GFR $=$ $170 \times[\mathrm{sCr} \text { concentration }(\mathrm{mg} / \mathrm{dL})]^{-0.999} \times$ (age) ${ }^{-0.176} \times$ [serum urea nitrogen concentration $(\mathrm{mg} / \mathrm{dL})]^{-0.17} \times$ [albumin concentration $(\mathrm{g} / \mathrm{dL})]^{0.318} \times(0.762$ if the patient is female $)$ $\times(1.18$ if the patient is black) [7].

CKD-EPI, expressed as a single equation, is GFR $=141 \times \min (\mathrm{sCr} / \mathrm{k}, 1)^{\alpha} \times \max$ $(\mathrm{sCr} / \mathrm{k}, 1)^{-1.209} \times 0.993^{\mathrm{Age}} \times 1.018$ (if female) $\times 1.159$ (if black), where $\mathrm{k}$ is 0.7 for females and 0.9 for males, and $\alpha$ is -0.329 for females and -0.411 for males (min in- dicates the minimum of $\mathrm{sCr} / \mathrm{k}$ or 1 and $\max$ indicates the maximum of $\mathrm{sCr} / \mathrm{k}$ or 1) [8]. Finally, sclerodermic patients were classified in subgroups based on stages of renal failure according to the Kidney Disease Outcomes Quality Initiative guidelines [9].

\section{Nailfold videocapillaroscopy}

Nailfold videocapillaroscopy (NVC) was performed with a videocapillaroscope (Pinnacle Studio Version 8) equipped with a $500 \times$ optical probe. The nailfold of the $2^{\text {nd }}$, $3^{\text {rd }}, 4^{\text {th }}$, and $5^{\text {th }}$ finger was examined in each patient. According to Cutolo et al. [10], patterns identified within the "SSc pattern" include early, active, and late. NVC is the best technique to evaluate microvascular damage in SSc patients.

\section{Clinical assessment}

Skin involvement was assessed using the modified Rodnan skin thickness score (mRSS), a validated measure of skin thickening in SSc. In the mRSS, skin thickening is assessed at 17 body sites by palpation and rated on a scale with values of 0 (normal), 1 (mild), 2 (moderate) or 3 (severe skin thickening). The total skin score is the sum of the individual skin assessments in the 17 body areas, with a possible range of 0 to 51 ; the higher the score, the greater the extent and severity of skin thickening [11]. Disease activity in SSc was measured using the Disease Activity Index (DAI) which consists of 10 weighted variables: total skin score $>14$, scleroderma, digital necrosis, arthritis, total lung capacity $<80 \%$, erythrocyte sedimentation rate $>30$, hypocomplementemia and changes in cardiopulmonary, skin, and vascular symptoms in the past month [12]. Disease severity was measured by the Disease Severity Scale (DSS). This scale assesses disease severity in 9 organs or systems, namely general health, peripheral vascular, skin, joint/ tendon, muscle and gastrointestinal tract, lungs, heart, and kidneys. Each organ/system is scored separately from 0 to 4 depending on whether there is no, mild, moderate, severe, or end-stage involvement [13]. 
Table 1. Association between estimated glomerular filtration rate (CKD-EPI and 7-variable MDRD) and epidemiological and clinical features of SSc patients.

\begin{tabular}{|l|c|c|c|c|c|c|}
\hline \multirow{2}{*}{} & \multicolumn{3}{|c|}{ CKD-EPI } & \multicolumn{3}{c|}{ 7-variable MDRD } \\
\cline { 2 - 7 } & $\beta$ & $\mathrm{r}$ & $\mathrm{p}$-value & $\beta$ & $\mathrm{r}$ & $\mathrm{p}$-value \\
\hline Age & -0.645 & -0.73 & $<0.0001$ & -0.635 & -0.624 & $<0.0001$ \\
\hline Disease duration & -0.365 & -0.240 & $<0.05$ & -0.345 & -0.291 & $<0.05$ \\
\hline RP duration & -0.152 & 0.298 & 0.08 & 0.102 & -0.234 & 0.61 \\
\hline mRSS & 0.416 & 0.149 & 0.27 & -0.077 & 0.232 & 0.62 \\
\hline DAI & 0.143 & -0.330 & 0.07 & -0.082 & 0.060 & 0.70 \\
\hline DSS & 0.156 & 0.240 & 0.18 & 0.073 & 0.042 & 0.72 \\
\hline
\end{tabular}

$\beta=$ standard regression coefficient. In the analysis, the estimated glomerular filtration rate (CKD-EPI and 7-variable MDRD) was entered as a dependent variable. The following factors were entered as independent variables: age, disease duration, Raynaud's phenomenon duration, mRSS, DAI, and DSS. RP = Raynaud's phenomenon; mRSS = modified Rodnan skin thickness score; DAI = Disease Activity Index; DSS = Disease Severity Scale.
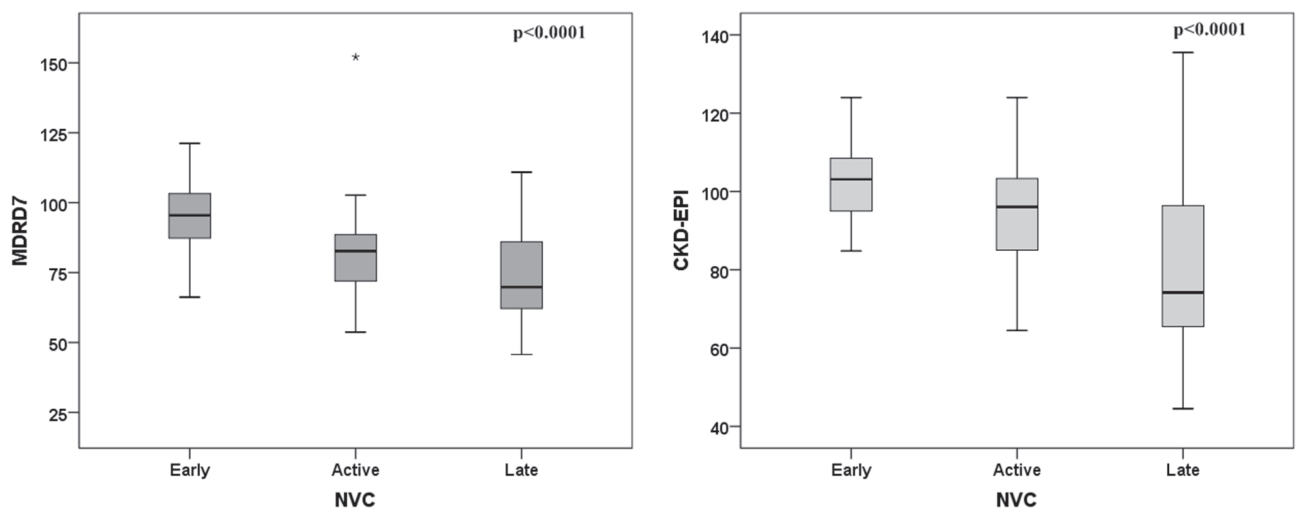

Figure 1. GFR evaluated by 7-variable MDRD and CKD-EPI equations in three capillaroscopic patterns.

\section{Statistical analysis}

All results are expressed as mean and standard deviation (SD). Commercial software was used for statistical analysis (SPSS version 20.0). The coefficients of skewness and kurtosis were used to evaluate normal distribution of data. Multiple regression analysis was done to assess the relationship between eGFR and demographic and clinical features (age, duration of disease, mRSS, DAI, DSS). Pearson product-moment correlation coefficient (r) was used to test for an association between numerical variables. Group comparisons were made by Student's unpaired 2-tailed t-test. $\chi^{2}$ or Fisher's exact tests were used to compare categorical variables as appropriate. A p-value $<0.05$ was considered significant.

\section{Results}

In all patients, $\mathrm{sCr}$ concentrations were normal $(0.75 \pm 0.17 \mathrm{mg} / \mathrm{dL})$. Median $24-\mathrm{h}$ proteinuria was $125 \pm 34 \mathrm{mg} / 24 \mathrm{~h}$. eGFR was $85 \pm 22 \mathrm{~mL} / \mathrm{min}$ and $91 \pm 19 \mathrm{~mL} / \mathrm{min}$ using 7-variable MDRD and CKD-EPI equations, respectively. Urinalysis showed normal urinary sediment in all SSc patients.

Age correlated negatively with eGFR when evaluated by 7-variable MDRD $(\mathrm{r}=-0.59, \mathrm{p}<0.0001)$ or CKD-EPI $(\mathrm{r}=-0.63$, $\mathrm{p}<0.0001)$. Duration of disease correlated negatively with eGFR when evaluated by 7 -variable MDRD $(r=-0.29, \mathrm{p}<0.01)$ or CKD-EPI $(r=-0.20, p<0.05)$. There were no correlations between eGFR and mRSS, DAI or DSS. These data are summarized in Table 1.

eGFR evaluated by 7-variable MDRD was not significantly different $(p>0.05)$ in patients with limited cutaneous SSc $(81 \pm 21$ $\mathrm{mL} / \mathrm{min})$ or diffuse cutaneous SSc $(90 \pm 23$ $\mathrm{mL} / \mathrm{min}$ ). Additionally, eGFR evaluated by CKD-EPI was not significantly different in patients with limited cutaneous SSc $(85 \pm 17$ $\mathrm{mL} / \mathrm{min})$ or diffuse cutaneous SSc $(99 \pm 19$ $\mathrm{mL} / \mathrm{min})$. 

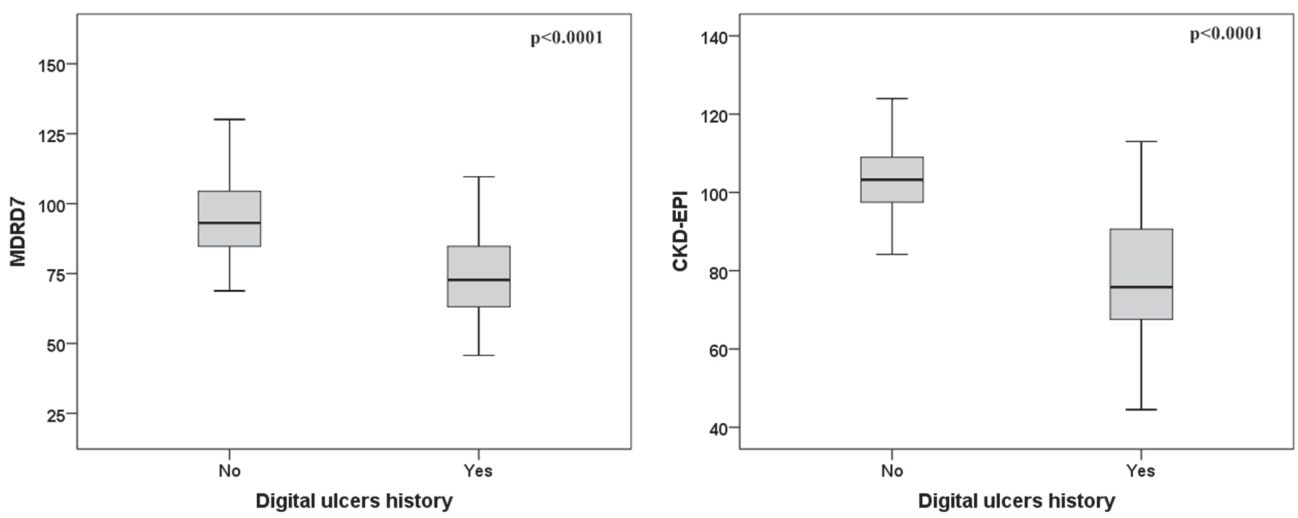

Figure 2. GFR evaluated by 7-variable MDRD and CKD-EPI equations in SSc patients with or without digital ulcer history.

The mean value of $\mathrm{sCr}$ concentrations was significantly different in the three capillaroscopic groups $(p<0.0001)$. The mean value of $\mathrm{sCr}$ concentrations increased with severity of capillaroscopic damage: early $0.64 \pm 0.15$, active $0.78 \pm 0.17$, and late $0.83 \pm 0.14 \mathrm{mg} / \mathrm{dL}$.

The mean value of eGFR evaluated by 7-variable MDRD or CKD-EPI was significantly different in the three capillaroscopic groups $(p<0.0001)$. The mean value of eGFR evaluated by 7-variable MDRD decreased with capillaroscopic damage severity: early $95 \pm 16 \mathrm{~mL} / \mathrm{min}$, active $86 \pm 25$ $\mathrm{mL} / \mathrm{min}$, and late $76 \pm 21 \mathrm{~mL} / \mathrm{min}$. Similarly, eGFR evaluated by CKD-EPI decreased with capillaroscopic damage severity: early $101 \pm 12 \mathrm{~mL} / \mathrm{min}$, active $95 \pm 17 \mathrm{~mL} / \mathrm{min}$, and late $82 \pm 21 \mathrm{~mL} / \mathrm{min}$ (Figure 1).

The mean value of eGFR evaluated by 7-variable MDRD or CKD-EPI was significantly different in SSc patients with or without digital ulcer (DU) history (Figure 2). The mean value of eGFR evaluated by 7-variable MDRD was significantly lower in SSc patients with DU history than in patients without DU history $(74 \pm 15 \mathrm{~mL} / \mathrm{min}$ vs. $97 \pm 23 \mathrm{~mL} / \mathrm{min}, \mathrm{p}<0.0001)$. eGFR evaluated by CKD-EPI was significantly lower in SSc patients with DU history than in patients without $(80 \pm 17 \mathrm{~mL} / \mathrm{min}$ vs. $105 \pm 12 \mathrm{~mL} /$ $\min , \mathrm{p}<0.0001$ ) (Figure 2). Conversely, $\mathrm{sCr}$ concentrations were significantly higher in SSc patients with DU history than in patients without $(0.83 \pm 0.20 \mathrm{~mL} / \mathrm{min}$ vs. $0.68 \pm 0.10$ $\mathrm{mL} / \mathrm{min}, \mathrm{p}<0.0001$ ).

\section{Discussion}

This study evaluated GFR by the MDRD and CKD-EPI equations in SSc patients without clinical renal involvement. The MDRD formula underestimated GFR compared to CKD-EPI. MDRD has been validated in patients with kidney impairment while CKD-EPI has been used in different populations, including healthy subjects. The CKDEPI equation has shown better performance in the higher ranges of GFR [7, 8]. Recently, Tent et al. [14] retrospectively evaluated the use of MDRD and CKD-EPI to monitor the long-term course of kidney function and to identify individuals with progressive kidney function loss. In their study, $\mathrm{sCr}$ at baseline was $1.30 \pm 0.52$, MDRD was $63 \pm 24$, and CKD-EPI was $70 \pm 26$. This shows acceptable performance of the CKD-EPI equation and a slight underestimation of mean function loss by the MDRD formula in the longterm follow-up of CKD patients.

GFR in patients with SSc appears to be normal or slightly reduced. The two formulas (7-variable MDRD and CKD-EPI) were found to be excellent indicators of renal function in patients with SSc.

Although age represents an independent risk factor for the reduction of eGFR, our study showed a negative correlation with disease duration. We can assume that eGFR, regardless of age, decreases with disease duration which in turn increases renal vascular damage.

We demonstrated that eGFR correlated negatively with severity of microvascular digital damage evaluated by NVC. eGFR was also lower in patients with a history of DUs than in those without. 
Many complications of SSc are vascular, including pulmonary arterial hypertension and SRC. Structural vascular damage occurs in many vascular beds concurring to pulmonary, renal, cardiac, and gastrointestinal complications [15]. In contrast to other SSc complications, renal involvement is asymptomatic with the exception of SRC [16]. A significant reduction in renal blood flow and elevated plasma renin activity was found in SSc patients with normal filtration [17]. Autopsy studies have demonstrated renal histopathologic changes in the majority of patients with SSc in which SRC and hypertension have not developed. Subintimal proliferation and luminal narrowing of small- and medium-sized arteries in the kidney are the most prominent findings. Arterial changes coexist with varying degrees of tubule atrophy, interstitial fibrosis, and glomerular obsolescence.

Intrarenal vascular damage is present early on in SSc without clinical renal involvement. In a previous study, Rosato et al. [18] demonstrated that intrarenal arterial stiffness was higher in SSc patients than in healthy controls and correlated with severity of capillaroscopic damage. Intrarenal stiffness showed a negative correlation with eGFR. The authors demonstrated that Doppler indices of intrarenal stiffness were reliable markers to predict the occurrence of new DUs. The pathophysiological mechanism of this slowly progressive form of chronic renal disease in SSc is unclear. Reduced renal blood flow plays a key role in the reduction of GFR. In all renal manifestations of SSc, chronic renal vasculopathy seems to be the main pathogenic mechanism. We can suppose that, in the initial phases of renal damage progression, resistance indices increase and GFR is normal or slightly reduced. This initial reduction of GFR is linked more to reduced blood inflow to intrarenal vessels than to reduced glomerular filtration capacity [19, 20]. GFR is further reduced with the progression of intrarenal vascular damage. The deterioration of GFR is due both to the reduction in intrarenal arteries blood inflow and glomerular injury. Secondary ischemic changes in the glomeruli may occur with the progression of renal ischemic injury. Glomerular injury is the determining factor in the onset of pathological urinary sediment (hematuria and proteinuria) and increased $\mathrm{sCr}$. The rel- evant factors mediating vascular changes in $\mathrm{SSc}$ include the renin-angiotensin system, profibrotic growth factors, transforming growth factor- $\beta$, connective tissue growth factor, and reactive oxygen species [21]. In a recent study, we demonstrated that intrarenal arterial elasticity showed a linear correlation with sympathetic activity in a group of SSc patients with normal $\mathrm{sCr}$ and high renal resistive index [22].

We can conclude that in SSc patients without renal involvement, eGFR decreases with severity of digital vascular damage. We can hypothesize that renal vascular damage, similar to Raynaud's phenomenon, represents the pathogenetic mechanism of the reduction of eGFR in early stages of the disease.

\section{Conflict of interest}

The authors declare no conflict of interest.

\section{References}

[1] Shanmugam VK, Steen VD. Renal manifestations in scleroderma: evidence for subclinical renal disease as a marker of vasculopathy. Int J Rheumatol. 2010; 2010; pii: 538589.

[2] Kingdon EJ, Knight CJ, Dustan K, Irwin AG, Thomas M, Powis SH, Burns A, Hilson AJ, Black $C M$. Calculated glomerular filtration rate is a useful screening tool to identify scleroderma patients with renal impairment. Rheumatology (Oxford). 2003; 42: 26-33

[3] Gigante A, Rosato E, Massa R, Rossi C, Barbano B, Cianci R, Molinaro I, Amoroso A, Salsano F. Evaluation of Chronic Kidney Disease Epidemiology Collaboration equation to estimate glomerular filtration rate in scleroderma patients. Rheumatology (Oxford). 2012; 51: 1426-1431.

[4] van den Hoogen F, Khanna D, Fransen J, Johnson SR, Baron M, Tyndall A, Matucci-Cerinic M, Naden RP, Medsger TA Jr, Carreira PE, Riemekasten G, Clements PJ, Denton CP, Distler O, Allanore Y, Furst DE, Gabrielli A, Mayes MD, van Laar JM, Seibold JR, et al. 2013 classification criteria for systemic sclerosis: an American College of Rheumatology/European League against Rheumatism collaborative initiative. Arthritis Rheum. 2013; 65: 2737-2747.

[5] LeRoy EC, Black C, Fleischmajer R, Jablonska S, Krieg T, Medsger TA Jr, Rowell N, Wollheim F. Scleroderma (systemic sclerosis): classification, subsets and pathogenesis. J Rheumatol. 1988; 15 : 202-205

[6] Wetzels JF, Kiemeney LA, Swinkels DW, Willems $H L$, den Heijer $M$. Age- and gender-specific reference values of estimated GFR in Caucasians: the Nijmegen Biomedical Study. Kidney Int. 2007; 72: 632-637. 
[7] Levey AS, Bosch JP, Lewis JB, Greene T, Rogers $N$, Roth D; Modification of Diet in Renal Disease Study Group. A more accurate method to estimate glomerular filtration rate from serum creatinine: a new prediction equation. Ann Intern Med. 1999; 130: 461-470.

[8] Levey AS, Stevens LA, Schmid CH, Zhang YL, Castro AF III, Feldman HI, Kusek JW, Eggers P, Van Lente F, Greene T, Coresh J; CKD-EPI (Chronic Kidney Disease Epidemiology Collaboration). A new equation to estimate glomerular filtration rate. Ann Intern Med. 2009; 150: 604-612.

[9] National Kidney Foundation. K/DOQI clinical practice guidelines for chronic kidney disease: evaluation, classification, and stratification. Am J Kidney Dis. 2002; 39 (Suppl 1): S1-S266.

[10] Cutolo M, Sulli A, Secchi ME, Paolino S, Pizzorni $C$. Nailfold capillaroscopy is useful for the diagnosis and follow-up of autoimmune rheumatic diseases. A future tool for the analysis of microvascular heart involvement? Rheumatology (Oxford). 2006; 45 (Suppl 4): iv43-iv46.

[11] Clements P, Lachenbruch P, Siebold J, White B, Weiner $S$, Martin R, Weinstein A, Weisman $M$, Mayes $M$, Collier D, et al. Inter and intraobserver variability of total skin thickness score (modified Rodnan TSS) in systemic sclerosis. J Rheumatol. 1995; 22: 1281-1285.

[12] Valentini G, Della Rossa A, Bombardieri S, Bencivelli $W$, Silman AJ, D'Angelo S, Cerinic MM, Belch JF, Black CM, Bruhlmann P, Czirják L, De Luca A, Drosos AA, Ferri C, Gabrielli A, Giacomelli $R$, Hayem $G$, Inanc M, McHugh NJ, Nielsen $H$, et al. European multicentre study to define disease activity criteria for systemic sclerosis. II. Identification of disease activity variables and development of preliminary activity indexes. Ann Rheum Dis. 2001; 60: 592-598.

[13] Medsger TA Jr, Silman AJ, Steen VD, Black CM, Akesson A, Bacon PA, Harris CA, Jablonska $S$ Jayson MI, Jimenez SA, Krieg T, Leroy EC, Maddison PJ, Russell ML, Schachter RK, Wollheim $F A$, Zacharaie H. A disease severity scale for systemic sclerosis: development and testing. J Rheumatol. 1999; 26: 2159-2167.

[14] Tent H, Waanders F, Krikken JA, Heerspink HJ, Stevens LA, Laverman GD, Navis G. Performance of MDRD study and CKD-EPI equations for long-term follow-up of nondiabetic patients with chronic kidney disease. Nephrol Dial Transplant. 2012; 27 (Suppl 3): iii89-iii95.

[15] Guiducci S, Giacomelli R, Cerinic MM. Vascular complications of scleroderma. Autoimmun Rev. 2007; 6: 520-523.

[16] Steen VD. Scleroderma renal crisis. Rheum Dis Clin North Am. 2003; 29: 315-333.

[17] Clements PJ, Lachenbruch PA, Furst DE, Maxwell M, Danovitch G, Paulus HE. Abnormalities of renal physiology in systemic sclerosis. A prospective study with 10-year followup. Arthritis Rheum. 1994; 37: 67-74.

[18] Rosato E, Barbano B, Gigante A, Molinaro I, Quarta S, Pisarri S, Amoroso A, Cianci R, Salsano $F$. Increased intrarenal arterial stiffness may predict the occurrence of new digital ulcers in systemic sclerosis. Arthritis Care Res (Hoboken). 2014; 66: 1380-1385.
[19] Matucci-Cerinic M, Kahaleh B, Wigley FM. Review: evidence that systemic sclerosis is a vascular disease. Arthritis Rheum. 2013; 65: 1953-1962.

[20] Cozzi F, Marson P, Cardarelli S, Favaro M, Tison T, Tonello M, Pigatto E, De Silvestro G, Punzi L, Doria A. Prognosis of scleroderma renal crisis: a long-term observational study. Nephrol Dial Transplant. 2012; 27: 4398-4403.

[21] Lee S, Lee S, Sharma K. The pathogenesis of fibrosis and renal disease in scleroderma: recent insights from glomerulosclerosis. Curr Rheumatol Rep. 2004; 6: 141-148.

[22] Gigante A, Rosato E, Liberatori M, et al. Autonomic dysfunction in patients with systemic sclerosis: Correlation with intrarenal arterial stiffness. Int J Cardiol. 2014: 177: 578-580. 